Article

\title{
Experimental Methods for Measuring the Viscous Friction Coefficient in Hydraulic Spool Valves
}

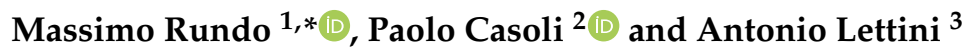 \\ 1 Department of Energy, Politecnico di Torino, 10129 Turin, Italy \\ 2 Department of Engineering and Architecture, University of Parma, 43124 Parma, Italy; paolo.casoli@unipr.it \\ 3 Casappa SpA, 43044 Lemignano di Collecchio, Italy; lettinia@casappa.com \\ * Correspondence: massimo.rundo@polito.it; Tel.: +39-011-090-4406
}

Citation: Rundo, M.; Casoli, P.;

Lettini, A. Experimental Methods for

Measuring the Viscous Friction

Coefficient in Hydraulic Spool Valves. Sustainability 2021, 13, 7174. https:// doi.org/10.3390/su13137174

Academic Editor: Pedro Javier Gamez-Montero

Received: 28 May 2021

Accepted: 24 June 2021

Published: 25 June 2021

Publisher's Note: MDPI stays neutral with regard to jurisdictional claims in published maps and institutional affiliations.

Copyright: (c) 2021 by the authors. Licensee MDPI, Basel, Switzerland. This article is an open access article distributed under the terms and conditions of the Creative Commons Attribution (CC BY) license (https:// creativecommons.org/licenses/by/ $4.0 /)$.
Abstract: In hydraulic components, nonlinearities are responsible for critical behaviors that make it difficult to realize a reliable mathematical model for numerical simulation. With particular reference to hydraulic spool valves, the viscous friction coefficient between the sliding and the fixed body is an unknown parameter that is normally set a posteriori in order to obtain a good agreement with the experimental data. In this paper, two different methodologies to characterize experimentally the viscous friction coefficient in a hydraulic component with spool are presented. The two approaches are significantly different and are both based on experimental tests; they were developed in two distinct laboratories in different periods of time and applied to the same flow compensator of a pump displacement control. One of the procedures was carried out at the Fluid Power Research Laboratory of the Politecnico di Torino, while the other approach was developed at the University of Parma. Both the proposed methods reached similar outcomes; moreover, neither method requires the installation of a spool displacement transducer that can significantly affect the results.

Keywords: hydraulic spool valve; viscous friction; load sensing control

\section{Introduction}

In the lumped parameter modelling of fluid power components, some coefficients that play a critical role in the simulation are typically unknown and not easy to be determined or to be found in the open literature. Moreover, in hydraulic systems, nonlinearities are responsible for critical behaviors that make it difficult to realize a reliable mathematical model for the numerical simulation. In most cases, the unknown parameters of a complex simulation model of an entire hydraulic system are selected a posteriori in order to obtain a good agreement with a few available experimental data. However, with this approach, the predictive capability of the model could be compromised, and its reliability in evaluating quantitatively the influence on the system performance of a parameter modification could be questionable, especially if the number of the unknown coefficients is high. In fact, it is possible that the same global behavior of the system could be obtained with different sets of coefficients; therefore, the real weight of some parameters may not be properly caught. In order to avoid this limitation, the best procedure, when possible, is to characterize as best as possible the single components with focused tests. In this way, the reliability of the system-level model can be improved.

With specific reference to continuous position fluid power valves, two types of coefficients are often difficult to be known with good accuracy: the discharge coefficient of the flow area, and the friction coefficient between the spool (sliding body) and the housing. The influence of the former is less critical due to the quite limited range of variation, typically between 0.6 and 0.9 , even if in some specific applications such a variation can nevertheless have a significant impact on the predicted system performance [1]. On the contrary, an incorrect definition of the friction coefficient value can lead one to predict erroneously 
system instability when the system is stable, and vice versa, due to a wrong representation of the physical phenomenon [2].

The knowledge of the dynamic friction behavior becomes relevant when a friction compensation strategy is implemented in the control systems, as reported in [3,4] for an electro-hydraulic excavator.

Generally, the friction force between a body sliding within a fixed casing has a nonlinear characteristic as a function of the relative speed. In this paper, only the viscous friction that is the main phenomenon affecting the investigated component is analyzed. As a matter of fact, no load is applied in the direction perpendicular to the spool axis, given that the radial forces are almost completely compensated; therefore, it is reasonable to assume that the lubricant film is thick enough to support the sliding body, and dissipations are due only to viscous losses [2]. Furthermore, there are other examples of hydraulic valves where only the viscous friction coefficient (speed dependent) is important, while the Coulomb friction (pressure dependent) can be neglected. This is the case, for instance, where the diether effect of a PWM (pulse-width modulation) control keeps the spool always in oscillation around an equilibrium position [5]. Moreover, all spools of the hydraulic valves are provided with annular grooves [6] for the radial balancing in order to minimize as much as possible the stick-slip phenomenon.

With reference to fluid power components in general, the scientific literature reports analysis of dynamic friction considering a hydraulic cylinder under various conditions of velocity; in the case considered in [3], the stick-slip phenomenon has been investigated; it is reported that when the sliding component starts to move again after a short dwell time, the force required is much smaller with respect to what found after a long dwell time. An explanation is found in the decrease of the lubricant film thickness, which is much smaller when the time at zero velocity is negligible.

In this paper, the investigated component is a part of a pump displacement control, where the sliding component oscillates continuously around an equilibrium position, and therefore the dwell time is very little, making the stick-slip phenomenon irrelevant. The component investigated in this paper has a key role in controlling the instantaneous displacement of an axial piston pump [7-9]. The authors have developed models of the pump [10] and of the hydraulic system for an excavator [11-14], where the pump with its displacement control is installed, a reliable model of the control permitted to correctly simulate the pump behavior during the transients that characterized the typical duty cycle of an excavator. To the best authors' knowledge, no experimental procedure is available in the open literature for the characterization of the viscous friction coefficient in such displacement controls. The values usually utilized by the scholars in their simulation models come from simplified theoretical hypotheses, such as the perfect coaxiality between the movable element and its seat. On the other hand, an experimental measurement needs a very specific "non-intrusive" approach, above all for small valves, on a dedicated test bench.

In this context the current paper presents two methodologies to assess experimentally the viscous friction coefficient that can be applied for any kind of hydraulic spool valve characterized by working conditions in which the dwell time between acceleration and deceleration of the spool is very small to make the stick-slip phenomenon not relevant. The methodologies reported in this paper are mainly based on experimental tests to collect data that can be used in the presented mathematical models to define the value of the viscous friction coefficient. The authors point out that the two methodologies were developed in two distinct laboratories in different periods of time; later, the authors have discovered that the outcomes were coincident, notwithstanding that the followed approaches were completely different. Hence, the importance of presenting in the same paper both methodologies is to demonstrate their mutual validation, since no other standard approach is available. One of the approaches was carried out at the Fluid Power Research Laboratory of the Politecnico di Torino (Turin, Italy), while the other was developed at the University of Parma (Italy). Both methods are based on the generation of a pressure oscillation and 
the dynamic measurement of the pressure in two different points of the test circuit. The signals were used to calculate the transfer function that relates the two pressures. The same function was also calculated thanks to a simulation model of the component, with which the value of the viscous friction coefficient that permits the best agreement between experimental and numerical data was determined. Both proposed methods do not require the installation of a spool displacement transducer that can significantly affect the results; this aspect has also been investigated, and the outcomes are presented in this paper.

The first methodology is based on the use of a servovalve for generating pressure oscillation at the inlet of a small pipe connected to the pilot chamber of the valve under test. The transfer function relates the pressures at the two ends of the pipe, and it is influenced by the oscillations of the spool. The second methodology developed at the University of Parma is based on experimental tests where the spool oscillations generated by the pressure ripple of a pump at the inlet port of the valve under test causes a time dependent flow rate at the outlet. The measurement of the fluid pressure both at the inlet and at the outlet of the component has permitted the transfer function to be defined. Therefore, not only the methods differ for the means of generating the oscillation of the spool, but also in the path of the fluid analyzed. In the first method, only the pilot line is considered with the valve ports closed, while in the second, the main flow through the valve is considered.

The paper is organized as follows: In Section 2, the tested component is described; in Section 3 the mathematical model concerning the first method is presented, to demonstrate the correlation between the measured fluid pressure and the viscous friction coefficient; in Section 4 the second method is presented mainly focusing on the experimental setup; a final discussion is reported in Section 5 .

\section{Description of the Tested Component}

The proposed methodologies were applied to a flow compensator (FC) that in a load sensing system has the function of regulating the flow rate by acting on the pump displacement. The logic governing the FC is to compare the maximum load pressure ( $\left.\mathrm{p}_{\mathrm{LS}}\right)$ of the hydraulic actuators with the pump delivery pressure $\left(\mathrm{p}_{\mathrm{S}}\right)$. In particular, the analyzed FC is mounted on an axial piston pump, and it has the function of regulating the swash plate angle.

In Figure 1 a simplified hydraulic scheme for feeding a single actuator is shown. The FC is a small three-port continuous position pilot valve, where the spool position depends on the pressure levels $p_{S}$ and $p_{L S}$ and on the force of an adjustable spring. The pump displacement is a function of the equilibrium of two actuators 1 and 2 with different diameters. The smaller actuator 2 is always connected to the delivery pressure, while the pressure acting on the larger actuator 1 is modulated by the FC. When the FC is not regulating (control in saturation), the actuator 1 is connected to the atmospheric pressure, and the actuator 2 holds the maximum pump displacement. On the contrary, when the valve spool is in equilibrium in an intermediate position, the pressure in the piston 1 is increased, its exerted force is able to balance the force of the piston 2, and the pump displacement is reduced. The condition of equilibrium of the spool implies that the delivery pressure $p_{S}$ is maintained equal to the load sensing pressure $p_{L S}$ incremented by a contribution given the adjustable spring, typically around 20 bar. In this way the FC maintains a fixed differential pressure across the main control valve, represented in the scheme by a variable restrictor $\mathrm{CV}$, so that the flow rate delivered to the actuator depends only on the flow area of $\mathrm{CV}$ and not on the load pressure $\mathrm{p}_{\mathrm{LS}}$.

Since a load sensing system is intrinsically closed loop pressure controlled, where the pilot line for transferring the load pressure $\mathrm{p}_{\mathrm{LS}}$ represents the feedback signal, it features poor behavior in damping high inertial loads [15]. Hence a possible risk is the instability that is also influenced by the viscous friction force of the FC. It is desirable that a simulation model of the hydraulic circuit could be able to predict the instability, but if the real damping coefficient of the spool of the FC is unknown, the reliability of the model for such a study could be questionable. For this reason, the spool of a load sensing pressure compensator 
represents a good example of application of the proposed methods for the measurement of the viscous friction.

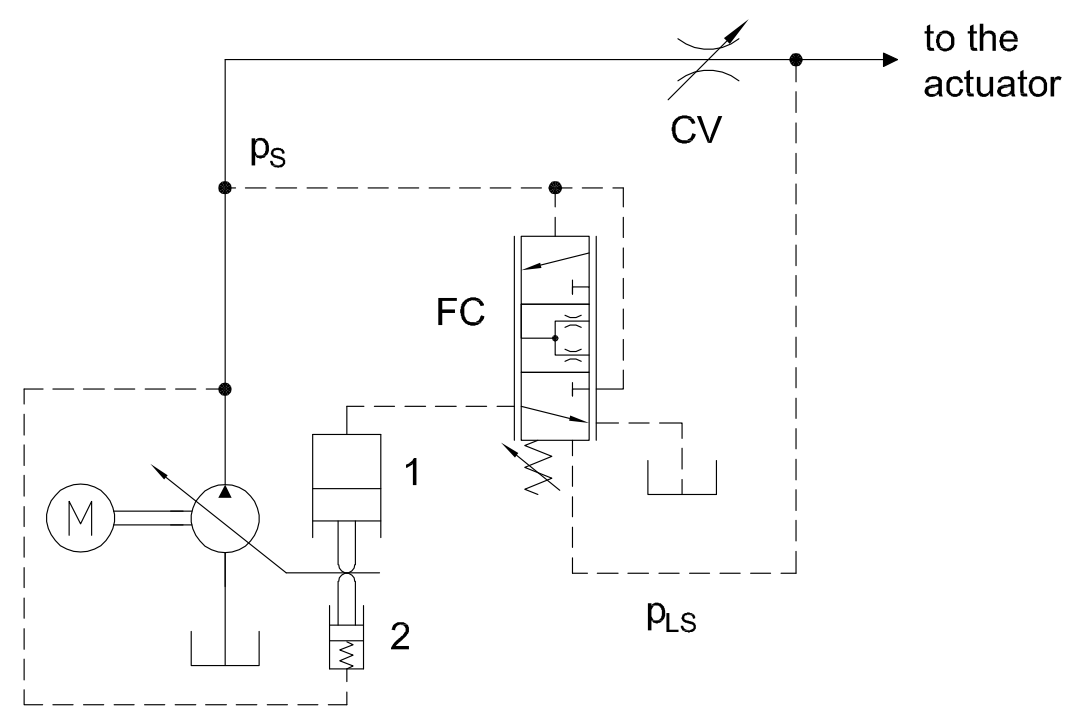

Figure 1. Hydraulic scheme of a load sensing control.

\section{First Method}

\subsection{Theoretical Analysis}

Let us consider a pipe with length $l$ and diameter d with a mass-spring system at one end (the mass $m$ includes also $1 / 3$ of the mass of the spring), as seen in Figure 2. At the opposite end, a variable pressure $\mathrm{p}_{1}$ is generated (i.e., a sinusoidal signal), while the spring chamber is connected at atmospheric pressure. As a consequence, the mass will oscillate, with the same frequency of the input signal, but with amplitude and phase delay that are influenced by the viscous friction between the mass and the housing. However, the measurement of the position $x$ of the mass by means of an LVDT will alter the dynamics of the system, above all if the size of the system is small. The solution is to measure both pressures $\mathrm{p}_{1}$ and $\mathrm{p}_{2}$ since their amplitude ratio and phase shift are also influenced by the viscous friction of the mass.

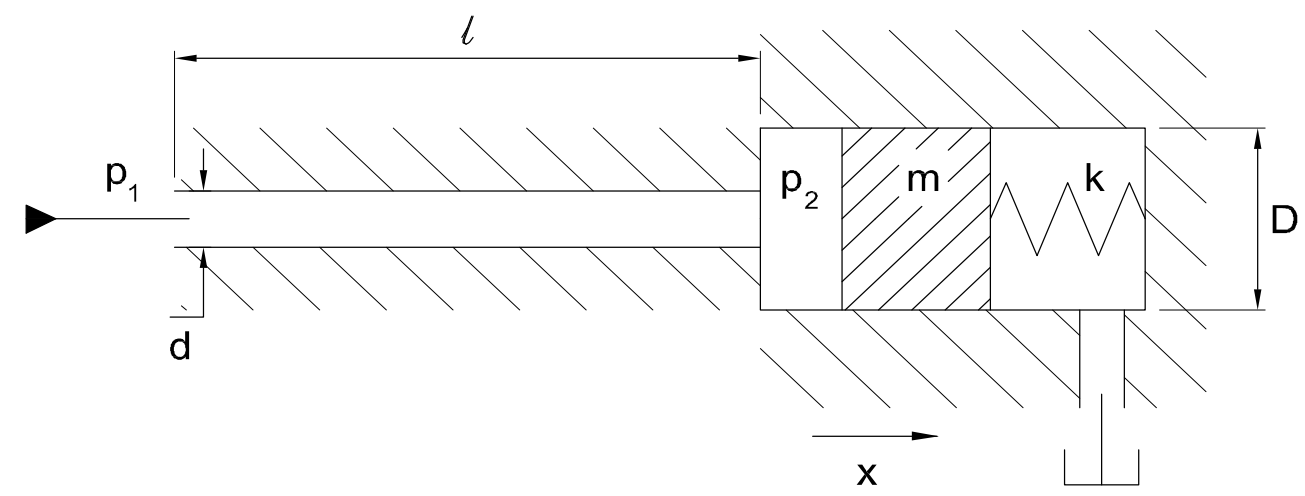

Figure 2. Scheme of the mass-spring-pipe system.

If, as a first approximation, a lumped parameter model RLC (resistive-inductivecapacitive) for the pipe is considered, it is possible to define the hydraulic inductance as follows:

$$
\mathrm{L}=\rho \frac{1}{\mathrm{a}}
$$


where $a$ is the cross section of the pipe, $\rho$ is the fluid density; the hydraulic resistance $R$ is

$$
\mathrm{R}=\frac{128 \mu \mathrm{L}}{\pi \mathrm{d}^{4}}
$$

where $\mu$ is the dynamic viscosity, and the hydraulic capacitance $C$ is

$$
C=\frac{V}{\beta}
$$

where $\mathrm{V}$ is the volume of the pipe (it also includes the volume of the pilot chamber), and $\beta$ is the fluid bulk modulus.

The equilibrium equation of the mass is

$$
\mathrm{m} \ddot{\mathrm{x}}+\mathrm{c} \dot{\mathrm{x}}+\mathrm{kx}=\mathrm{p}_{2} \mathrm{~A}
$$

where $\mathrm{A}$ is the frontal surface of the mass, while the equilibrium of the fluid in the pipe is

$$
\mathrm{LQ}+\mathrm{RQ}=\mathrm{p}_{1}-\mathrm{p}_{2}
$$

where $Q$ is the volumetric flow rate. The continuity equation is

$$
\dot{\mathrm{p}}_{2} \mathrm{C}=\mathrm{Q}-\mathrm{A} \dot{\mathrm{x}} .
$$

The following quantities are also defined:

- mechanical natural frequency:

$$
\omega_{\mathrm{m}}=\sqrt{\frac{\mathrm{k}}{\mathrm{m}}}
$$

- mechanical damping ratio:

$$
\xi_{\mathrm{m}}=\frac{\mathrm{c}}{2 \sqrt{\mathrm{mk}}}
$$

- hydraulic natural frequency:

$$
\omega_{\mathrm{h}}=\sqrt{\frac{1}{\mathrm{LC}}}
$$

- $\quad$ hydraulic damping ratio:

$$
\xi_{\mathrm{h}}=\frac{\mathrm{R}}{2} \sqrt{\frac{\mathrm{C}}{\mathrm{L}}}
$$

From Equation (4), the transfer function that relates the mass position with the pressure in the pilot chamber can be obtained:

$$
\mathrm{F}_{1}(\mathrm{~s})=\frac{\mathrm{x}}{\mathrm{p}_{2}}=\frac{\frac{\mathrm{A}}{\mathrm{m}}}{\mathrm{s}^{2}+2 \xi_{\mathrm{m}} \omega_{\mathrm{m}} \mathrm{s}+\omega_{\mathrm{m}}^{2}}
$$

while the combination of Equations (4)-(6) allows obtaining the transfer function that relates the pressures $p_{1}$ and $p_{2}$ (more details are available in reference [16]):

$$
F_{2}(s)=\frac{p_{2}}{p_{1}}=\frac{\omega_{h}^{2}\left(s^{2}+2 \xi_{m} \omega_{m} s+\omega_{m}^{2}\right)}{s^{4}+a_{3} s^{3}+a_{2} s^{2}+a_{1} s+a_{0}}
$$

where

$$
\begin{gathered}
\mathrm{a}_{3}=2\left(\xi_{\mathrm{m}} \omega_{\mathrm{m}}+\xi_{\mathrm{h}} \omega_{\mathrm{h}}\right) \\
\mathrm{a}_{2}=\omega_{\mathrm{m}}^{2}+\omega_{\mathrm{h}}^{2}+4 \xi_{\mathrm{m}} \xi_{\mathrm{h}} \omega_{\mathrm{m}} \omega_{\mathrm{h}}+\frac{\mathrm{A}^{2}}{\mathrm{mC}}
\end{gathered}
$$




$$
\begin{gathered}
\mathrm{a}_{1}=2\left(\xi_{\mathrm{h}} \omega_{\mathrm{h}} \omega_{\mathrm{m}}^{2}+\xi_{\mathrm{m}} \omega_{\mathrm{m}} \omega_{\mathrm{h}}^{2}+\xi_{\mathrm{h}} \omega_{\mathrm{h}} \frac{\mathrm{A}^{2}}{\mathrm{mC}}\right) \\
\mathrm{a}_{0}=\omega_{\mathrm{m}}^{2} \omega_{\mathrm{h}}^{2} .
\end{gathered}
$$

The transfer function $\mathrm{F}_{2}$ has two natural frequencies, since the denominator is of the 4th order. Such frequencies can be calculated analytically only if the dissipative terms c and $R$ are neglected; however, the main influence of such terms is on the damping and not on the frequency values that therefore can be expressed by Equation (17):

$$
\omega_{1,2}=\sqrt{\frac{1}{2}\left(\omega_{\mathrm{h}}^{2}+\omega_{\mathrm{m}}^{2}+\frac{\mathrm{A}^{2}}{\mathrm{mC}}\right) \mp \sqrt{\frac{1}{4}\left(\omega_{\mathrm{h}}^{2}+\omega_{\mathrm{m}}^{2}+\frac{\mathrm{A}^{2}}{\mathrm{mC}}\right)^{2}-\omega_{\mathrm{m}}^{2} \omega_{\mathrm{h}}^{2}}}
$$

The function $\mathrm{F}_{2}$ has also two complex conjugate zeros coincident with the poles of the function $\mathrm{F}_{1}$.

The transfer function (12). can be obtained experimentally by measuring two pressures. It must be highlighted that the quantities relative to the pipe $L$ and $R$ can be evaluated very accurately. There can be some uncertainties about the evaluation of the fluid bulk modulus (considering also the possible fraction of dissolved air), but it has an influence only at high frequencies far away from the range of interest. Regarding the mass-spring system, the only unknown is the friction coefficient $c$; therefore, the experimental transfer function $\mathrm{F}_{2}$ can be used for determining $\mathrm{c}$.

\subsection{Numerical Case}

For better understanding the effect of the viscous friction coefficient, the transfer function $\mathrm{F}_{2}$ is calculated using the same parameters of the pipe and of the fluid used in the experimental tests described in Section 3.3. It must be noted that the spring stiffness was deliberately reduced with respect to the original control valve in order to lower the value of the first frequency given by Equation (17). In Table 1 the calculated quantities are listed.

Table 1. Numerical values of the calculated quantities.

\begin{tabular}{cccccc}
\hline Variable & Value & Unit & Variable & Value & Unit \\
\hline $\mathrm{L}$ & $2.182 \cdot 10^{7}$ & $\mathrm{~kg} / \mathrm{m}^{4}$ & $\omega_{m}$ & 108 & $\mathrm{~Hz}$ \\
$\mathrm{R}$ & $1.935 \cdot 10^{9}$ & $\mathrm{~Pa} \cdot \mathrm{s} / \mathrm{m}^{3}$ & $\xi_{m}$ & 0.126 & - \\
$\mathrm{C}$ & $5.660 \cdot 10^{-15}$ & $\mathrm{~m}^{3} / \mathrm{Pa}$ & $\omega_{h}$ & 453 & $\mathrm{~Hz}$ \\
$\mathrm{a}_{0}$ & $3.731 \cdot 10^{12}$ & - & $\xi_{h}$ & 0.0155 & - \\
$\mathrm{a}_{1}$ & $2.567 \cdot 10^{9}$ & - & $\omega_{1}$ & 67 & $\mathrm{~Hz}$ \\
$\mathrm{a}_{2}$ & $2.140 \cdot 10^{7}$ & - & $\omega_{2}$ & 733 & $\mathrm{~Hz}$ \\
$\mathrm{a}_{3}$ & $2.602 \cdot 10^{2}$ & - & & & \\
\hline
\end{tabular}

It can be noticed that $\omega_{1}<\omega_{\mathrm{m}}<\omega_{\mathrm{h}}<\omega_{2}$. The transfer function $\mathrm{F}_{2}(\mathrm{~s})$ is plotted in Figure 3 in terms of magnitude and phase shift.

The transfer function in the frequency range around $\omega_{1}-\omega_{\mathrm{m}}$ is highly influenced by the viscous friction coefficient c, as shown in Figure 4, therefore, it is enough to test the system up to a maximum frequency of the order of $\omega_{\mathrm{m}}$. It can be convenient to use a low stiffness spring; in this way it is possible to limit the maximum frequency of the input pressure $\mathrm{p}_{1}$ with two advantages:

- It is easier to generate the sinusoidal signal with a reasonably high amplitude;

- If the mechanical frequency $\omega_{\mathrm{m}}$ is far away from the hydraulic frequency $\omega_{h}$, the transfer function around the lower natural frequency $\omega_{1}$ is mainly influenced by the mechanical system mass-spring and not by the dynamics of the pipe; therefore, any uncertainty in the simulation of the hydraulic system has a negligible influence on the evaluation of the friction coefficient of the mass. 


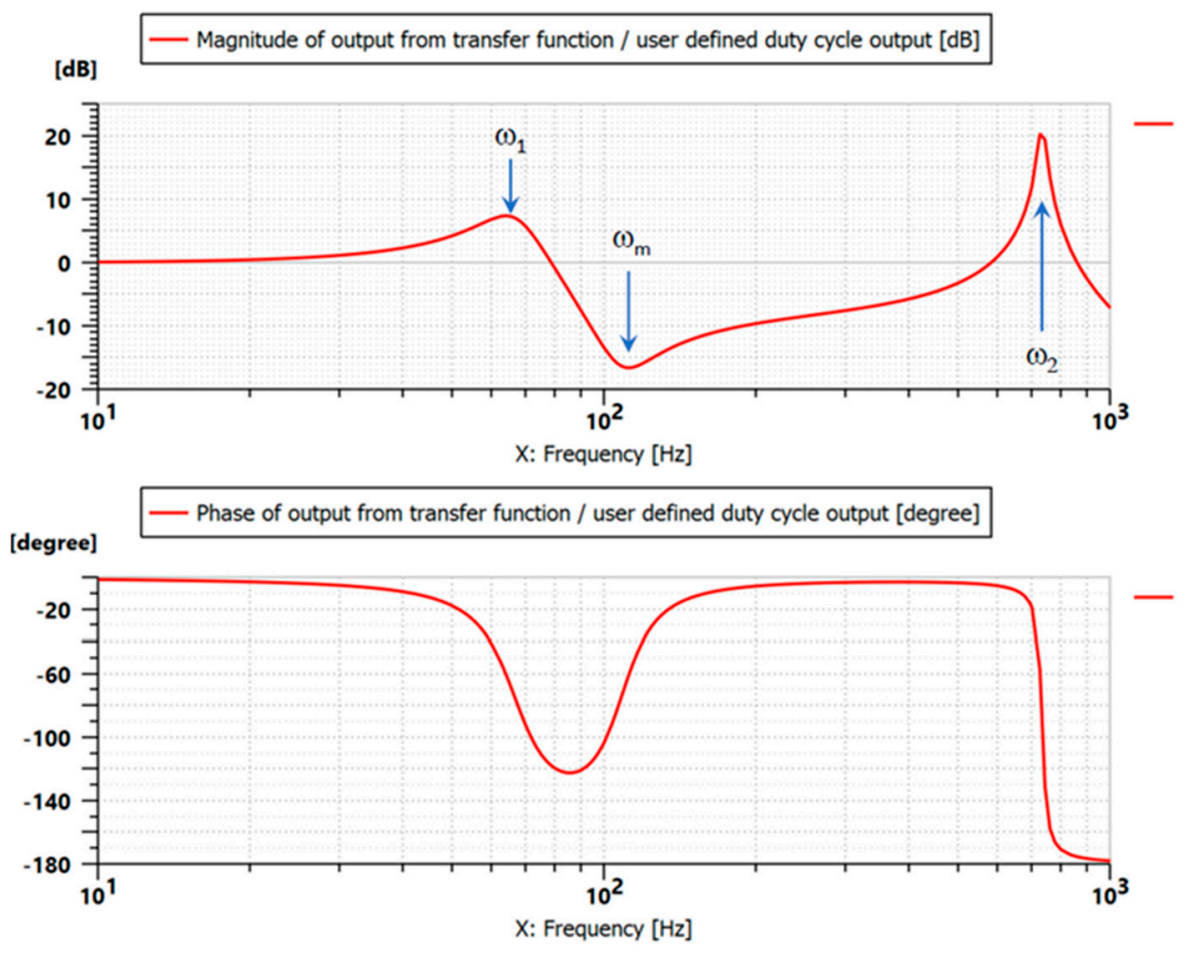

Figure 3. Magnitude and phase of the transfer function $F_{2}$.
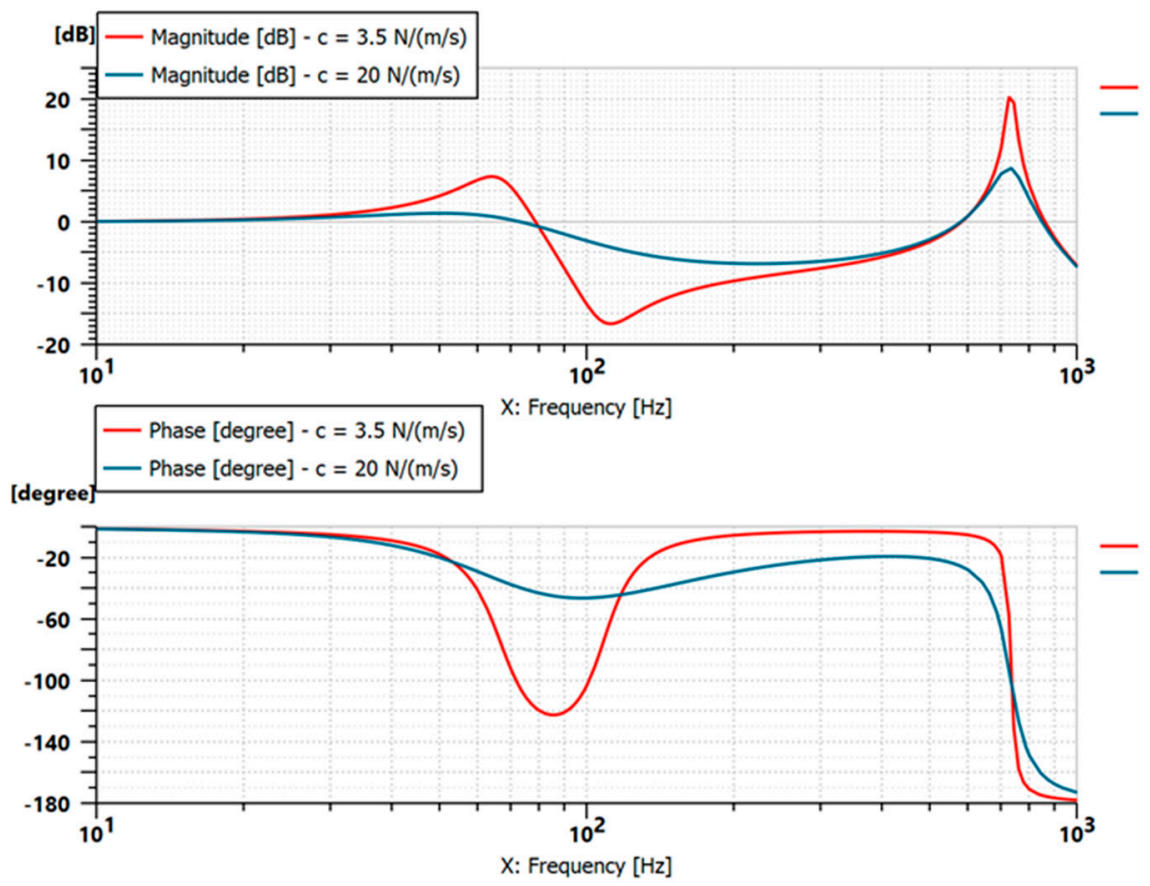

Figure 4. Influence of the friction coefficient $c$ on the transfer function $F_{2}$.

For a better representation of the real system, a distributed model of the pipe must be considered for contrasting the experimental data, and this implies a slight variation of the Bode diagram with respect to the simplified lumped parameter model presented in the Section 3.1. However, as demonstrated hereinafter, the shape of the function and the effect of the friction coefficient are the same. 


\subsection{Experimental Procedure}

The hydraulic scheme of the test circuit is reported in Figure 5. A Moog 76-103 nozzleflapper servovalve was used to generate a pseudo-sinusoidal signal $p_{1}$ at the inlet of the pipe. The servovalve was fed (supply line) at constant pressure by a pressure reducing valve. A manual variable restrictor $R 1$, connected with the return line, was mounted downstream the working port A of the servovalve, while port B was closed. The LS control was connected through the pipe to the junction J located between the servovalve and the manual restrictor. The spring chamber (LS signal) was connected directly to atmosphere, while port A was closed. Two GS XPM5 pressure transducers, each with a measuring range 0-50 absolute bar, were mounted at the two ends of the pipe. The oil temperature was measured by means of the sensors mounted in the inlet and return lines. The pressure in the junction J was modulated by the flow area of the manual restrictor and of the servovalve. In fact, once a suitable value of the flow area of the manual restrictor is set, if a sinusoidal input current is supplied to the servovalve, then an oscillating pressure is generated in the junction J. A photo of the hydraulic circuit is shown in Figure 6.

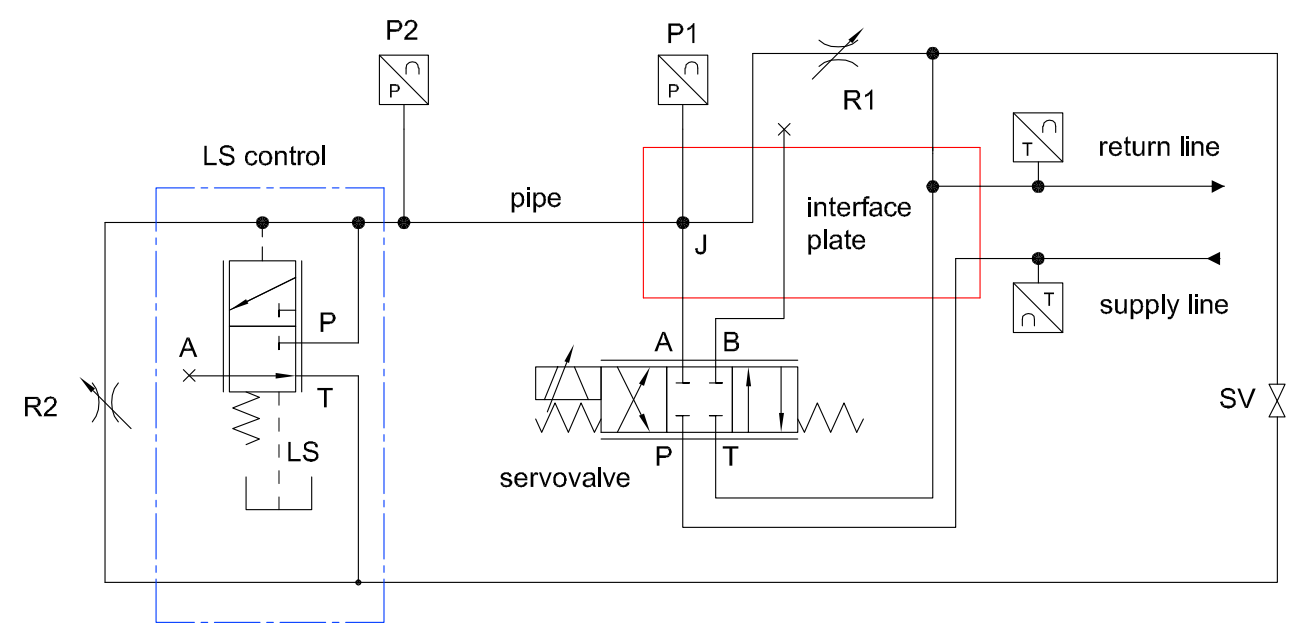

Figure 5. Layout of the test rig.

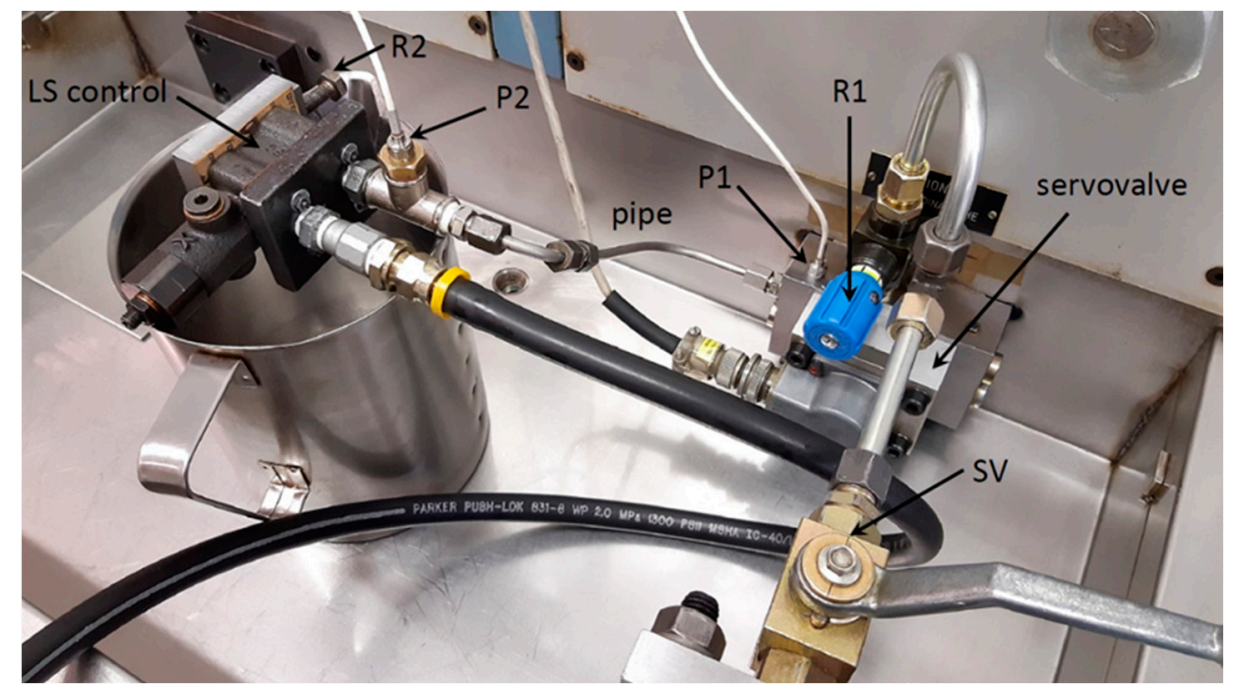

Figure 6. Photo of the test rig.

A plate with a screw was mounted on the upper side of the control (Figure 7). The screw behaves as a restrictor (R2) with which it is possible to connect directly the ports $\mathrm{P}$ and T of the LS control. 


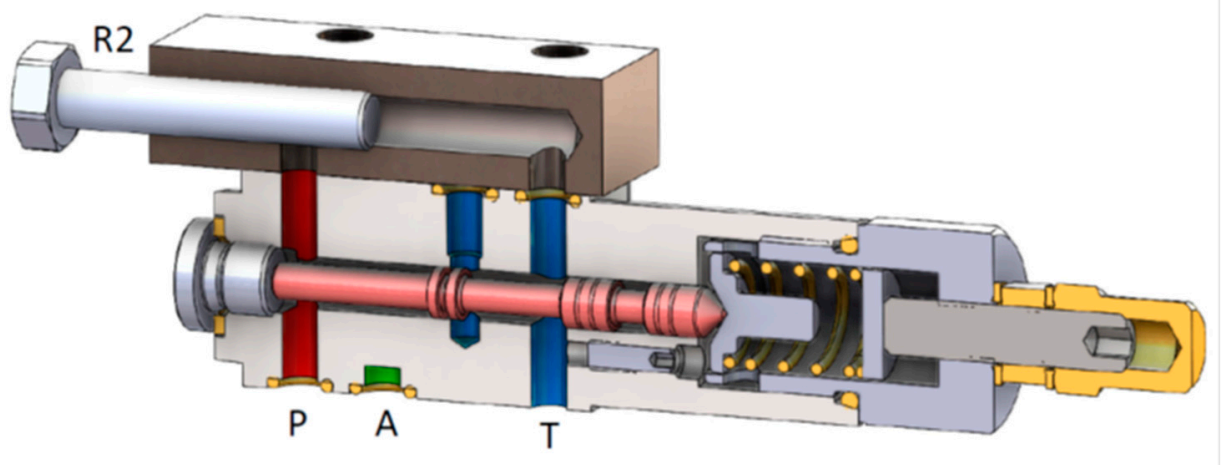

Figure 7. Cross section of the LS control in the configuration for the tests (by-pass P-T through R2 closed).

Before executing the test, a warm-up procedure was performed. The shut-off valve $\mathrm{SV}$ and the restrictor R2 remained open, and a constant input signal was supplied to the servovalve in order to obtain a continuous flow of oil from the port $A$ of the servovalve through the pipe, the LS control, the valves R2 and SV, and finally towards the return line. During this phase it is possible to make the oil temperature homogeneous in the entire circuit and to heat the body of the valve.

For the execution of the test, the shut-off valve and the restrictor R2 remained closed. The pressure at port $\mathrm{P}$ of the servovalve was imposed at 15 bar. A proper combination of the flow area of the manual restrictor and of the mean value of the input signal for the servovalve had be set in order to obtain a mean pressure at the port $\mathrm{A}$ of about 6 bar. Moreover, a suitable value of the amplitude of the input signal was determined to make the pressure $\mathrm{p}_{1}$ oscillate between 3 and $9 \mathrm{bar}$ at $5 \mathrm{~Hz}$. A control and data acquisition program was developed in the NI Labview ${ }^{\circledR}$ to perform the test. The software generates trends of sinusoidal signals with increasing frequencies, and at the end of each stage the amplitude and the phase shift of the ratio between the pressures $\mathrm{p}_{2}$ and $\mathrm{p}_{1}$ are calculated. For the present study, the frequency was increased from $10 \mathrm{~Hz}$ to $150 \mathrm{~Hz}$ with a logarithmic scale, and for each frequency value the Bode diagram was calculated on a total time interval of about 4 seconds. The sampling frequency used for acquiring the pressure signals was $10 \mathrm{kHz}$. The results obtained at $40{ }^{\circ} \mathrm{C}$ with ISO VG 46 oil in six different tests are shown in Figures 8 and 9. Before each test, the warm-up procedure was performed. Very good repeatability in both magnitude and phase was observed. Moreover, in spite of the simplifications used for determining the transfer function $\mathrm{F}_{2}$ plotted in Figure 2, the experimental function was very similar not only qualitatively, but also quantitatively.

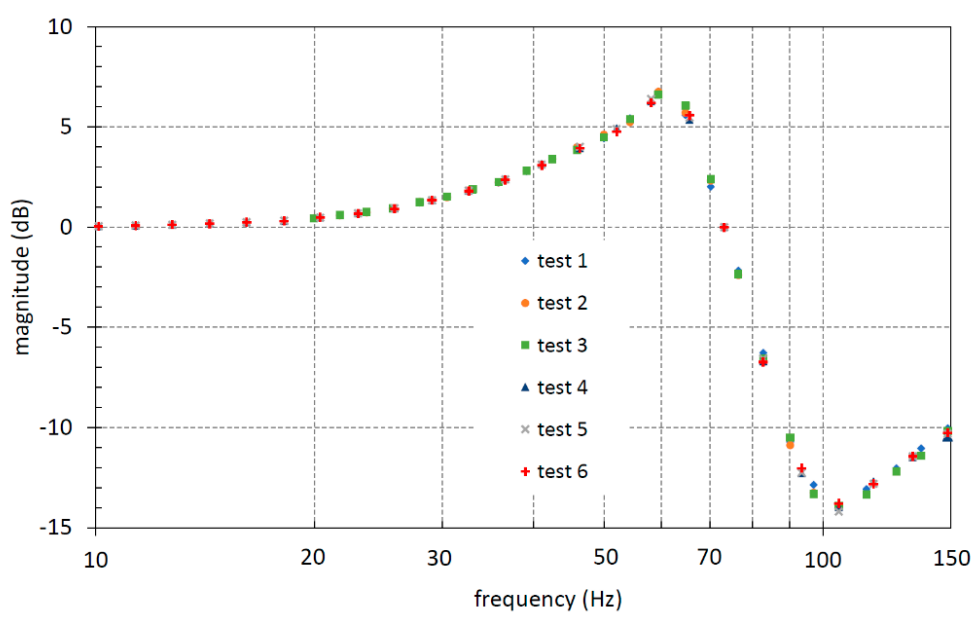

Figure 8. Experimental Bode diagram at $40^{\circ} \mathrm{C}$. 


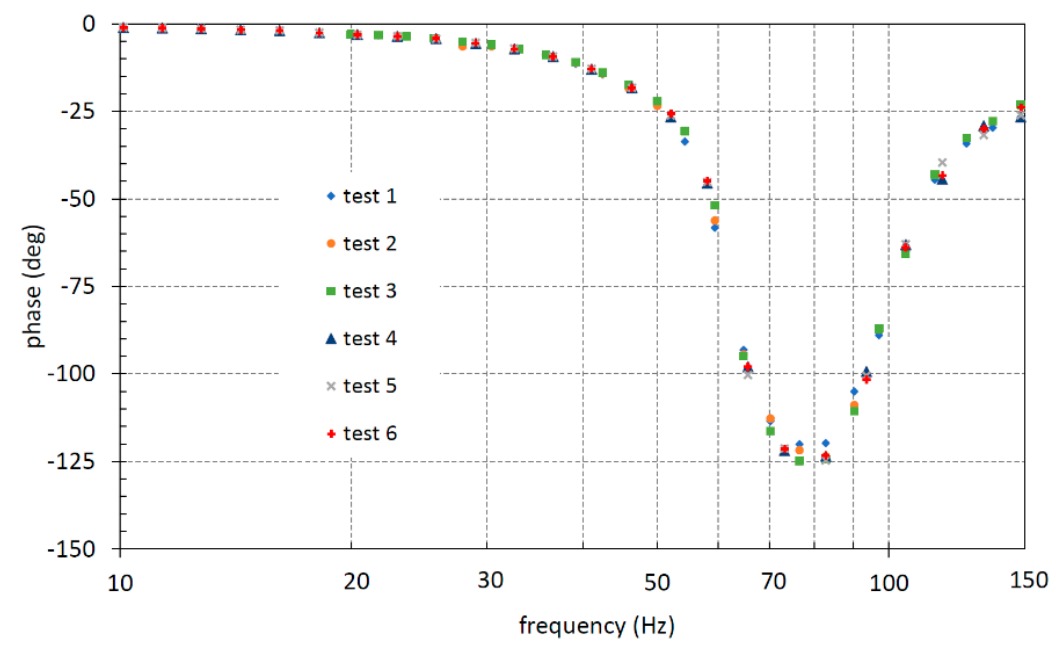

Figure 9. Experimental phase delay at $40^{\circ} \mathrm{C}$.

\subsection{Evaluation of the Friction Coefficient}

The part of the circuit shown in Figure 6 constituted by the pipe and the LS control was simulated with the maximum possible detail in Simcenter Amesim (Figure 10). A pressure source represents the inlet of the pipe (pressure $p_{1}$ ), while a fixed hydraulic capacity simulates the volume in the $\mathrm{T}$ junction where the transducer for measuring $\mathrm{p}_{2}$ is mounted. The pipe is simulated with a distributed parameter RLC model with 12 internal nodes and frequency dependent friction with 5 states. It was checked that such a pipe model gives the same results, in terms of time response, of a CFD 1D model that cannot be used for a linear analysis.

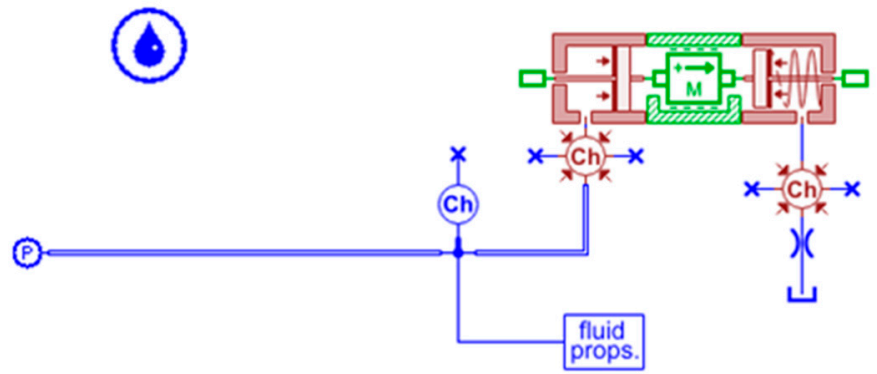

Figure 10. Amesim model of the pipe-mass-spring system.

The pipe between the fixed capacity and the variable capacity of the pilot chamber represents the volume in the fitting that connects the T junction with the LS control, and it is simulated with a OD RL model (inertia + friction). The mass taken into account is the mass of the spool and of the spring seat, one third of the mass of the spring, and the mass of oil in the annular volume around the spool. The spring stiffness was measured experimentally. The simulations were executed by supplying a pressure step for different values of the friction coefficient and by performing a linear analysis using as a control variable the pressure source and as an observer state the pressure in the fixed capacity (T junction). The simulations were contrasted with the experimental data for finding the value of the friction coefficient that gives the best match. The Figure 11 shows the results at $40{ }^{\circ} \mathrm{C}$; considering the region of maximum amplitude, the best value of $\mathrm{c}$ was between 3 and $4 \mathrm{~N} /(\mathrm{m} / \mathrm{s})$. 


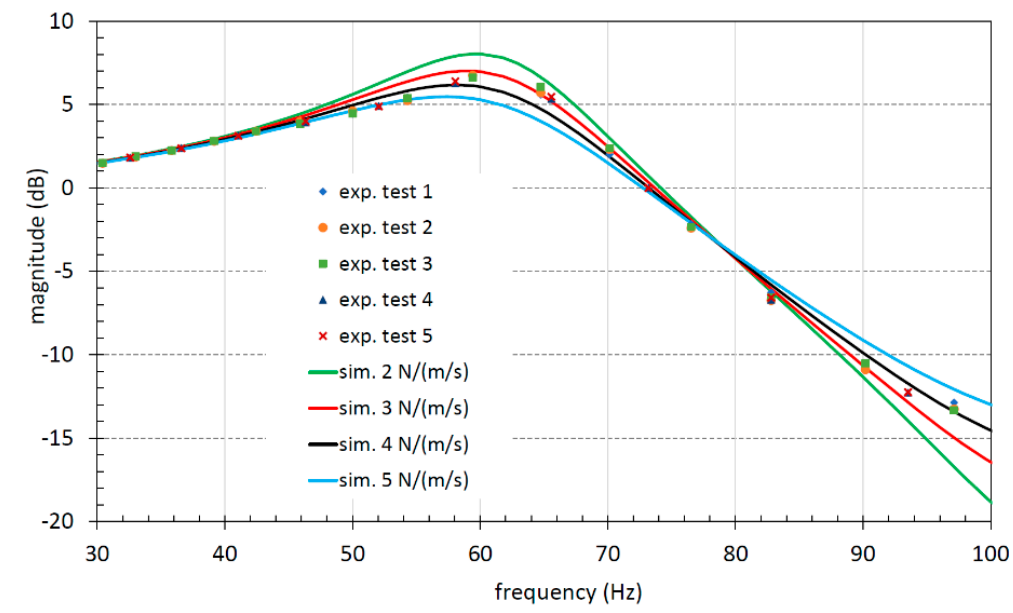

Figure 11. Comparison between simulated and experimental Bode diagram at $40{ }^{\circ} \mathrm{C}$.

The test was repeated at lower temperatures. At $30^{\circ} \mathrm{C}$ (Figure 12), a value between 5 and $6 \mathrm{~N} /(\mathrm{m} / \mathrm{s}$ ) could be estimated, while at ambient temperature (Figure 13), c was reasonably between 7 and $9 \mathrm{~N} /(\mathrm{m} / \mathrm{s})$.

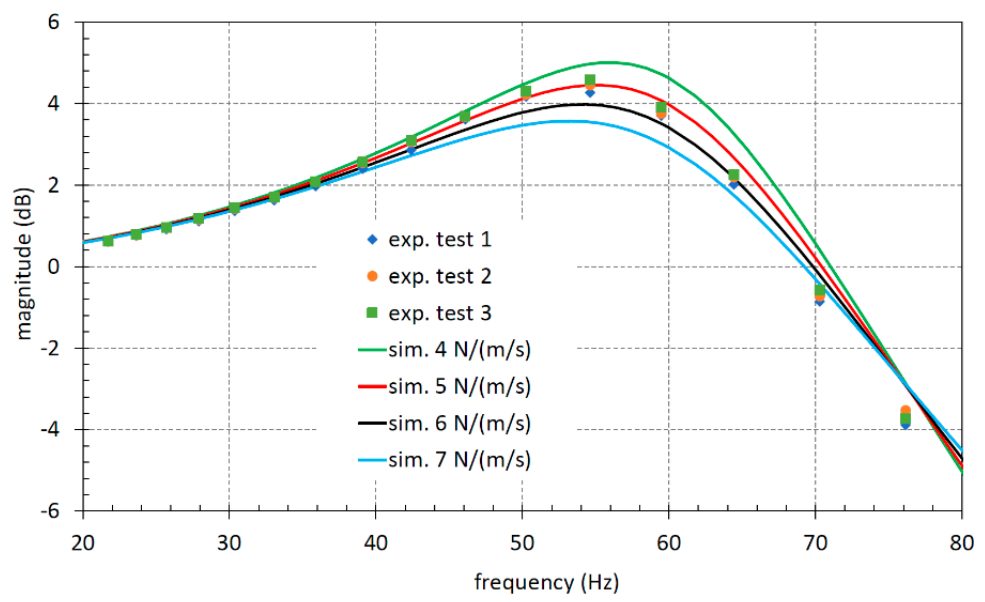

Figure 12. Comparison between simulated and experimental Bode diagram at $30^{\circ} \mathrm{C}$.

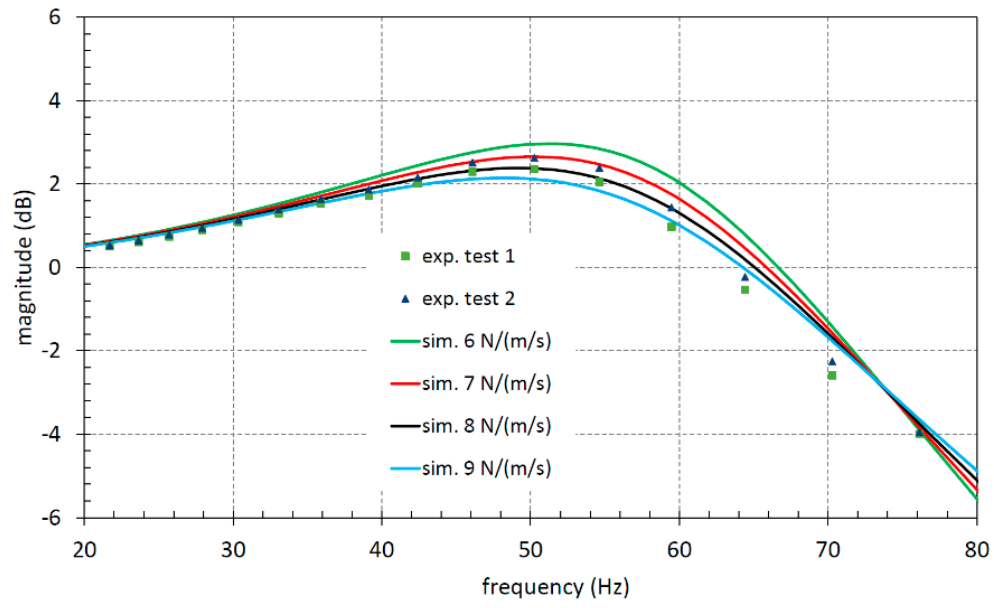

Figure 13. Comparison between simulated and experimental Bode diagram at $22{ }^{\circ} \mathrm{C}$.

It is evident that the oil temperature had a large influence on the friction coefficient. In Figure 14 for each value of the corresponding dynamic viscosity, the estimated range 
of the friction coefficient was plotted. Moreover, the mean values of each range were also interpolated with a regression line, and the equation and $\mathrm{R}^{2}$ were also indicated. It can be noticed that the friction coefficient can be considered proportional to the viscosity with a high degree of confidence; moreover, the straight line passes very close to the origin of the axes. Therefore, the results shown in Figure 14 demonstrate that the nature of the friction is manly viscous, since it tends to zero when the viscosity tends to zero.

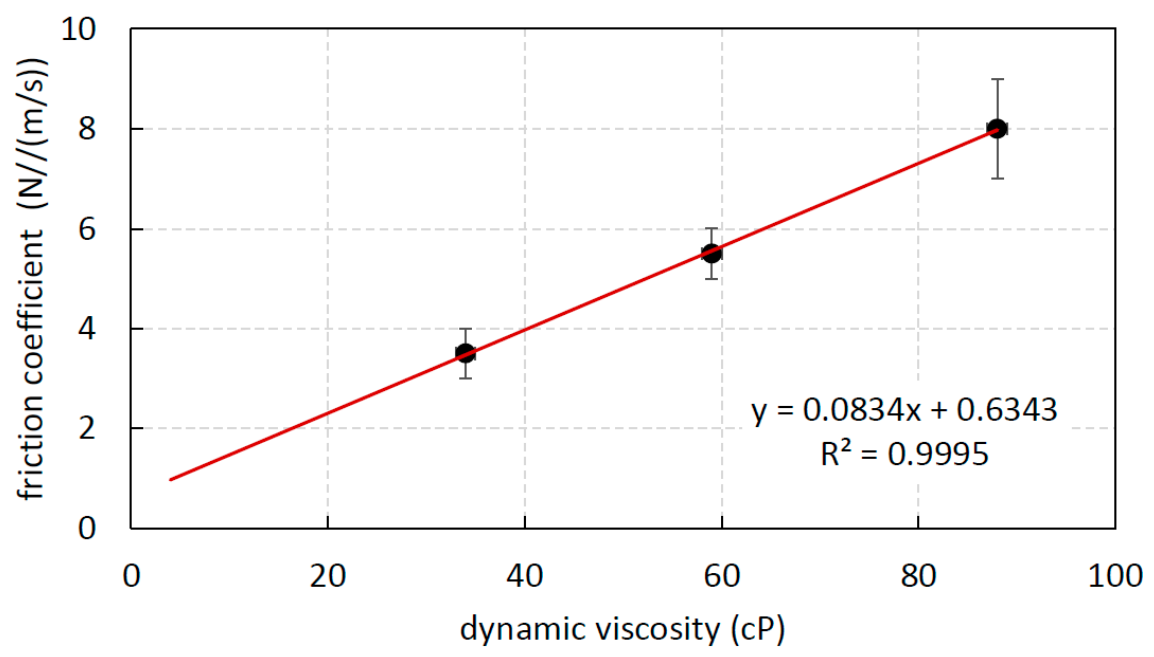

Figure 14. Measured friction coefficient as a function of the dynamic viscosity.

\section{Second Method}

In this section, the second methodology to define the value of the friction coefficient is presented. This approach is mainly based on experimental tests where the component has been excited in order to evaluate its dynamic response. Additionally, this methodology permits the component to be kept unchanged without the addition of a spool displacement transducer that changes the mass of the spool in a significant manner and adds further friction losses due to the spool of the transducer. In this second methodology, the use of a servovalve is not necessary, but a cheaper gear pump was used to excite the component. The ISO scheme of the circuit is reported in Figure 15.

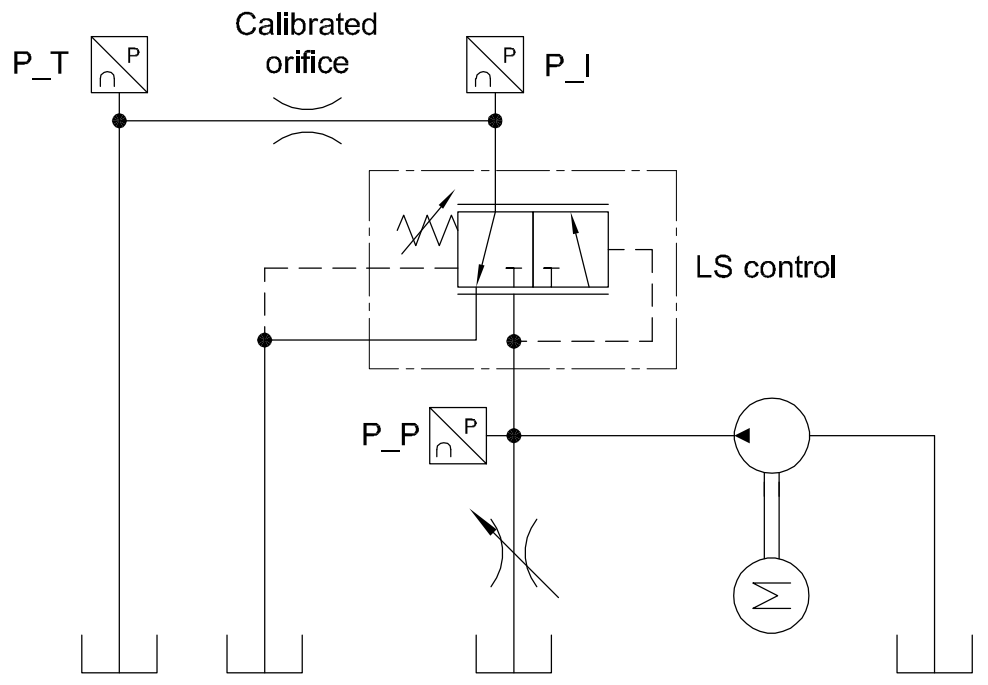

Figure 15. ISO scheme of the experimental setup.

The component was connected to the delivery line of a gear pump, the flow ripple of which generates a pressure ripple that dynamically excites the spool of the component. As 
is well known, it is not possible to measure a flow ripple with a high bandwidth instrument, unless using complex and indirect methods [17]; therefore, the fluid pressure ripple at the inlet of the component was acquired during the tests. The fundamental frequency of the pressure ripple (P_P) depends on the pump speed that can be easily changed during the tests, and then the spool can be excited at different conditions. The spool oscillations generated by the pressure ripple cause a time dependent flow rate at the outlet (line I) that once again cannot be measured. As reported in Figure 15, a calibrated orifice was introduced along the return line for converting the flow ripple in a measurable pressure ripple (P_I), and the size of this orifice was defined after several tests with different size diameters. The target was, on one hand, to generate an average pressure level to avoid too low minimum values; on the other hand, the average pressure could not be too high in order to neglect the effect of fluid compressibility. The pressure at the inlet $(\mathrm{P})$ was set at an average value of $30 \mathrm{bar}$ and $50 \mathrm{bar}$. The sensors were installed as close as possible to the component, and the entire layout was compacted to reduce the volume of fluid that could induce compressibility effects. Figure 16 reports a picture of the component installed on the test bench with sensors. All tests were carried out by setting the fluid temperature equal to $40^{\circ} \mathrm{C}$.

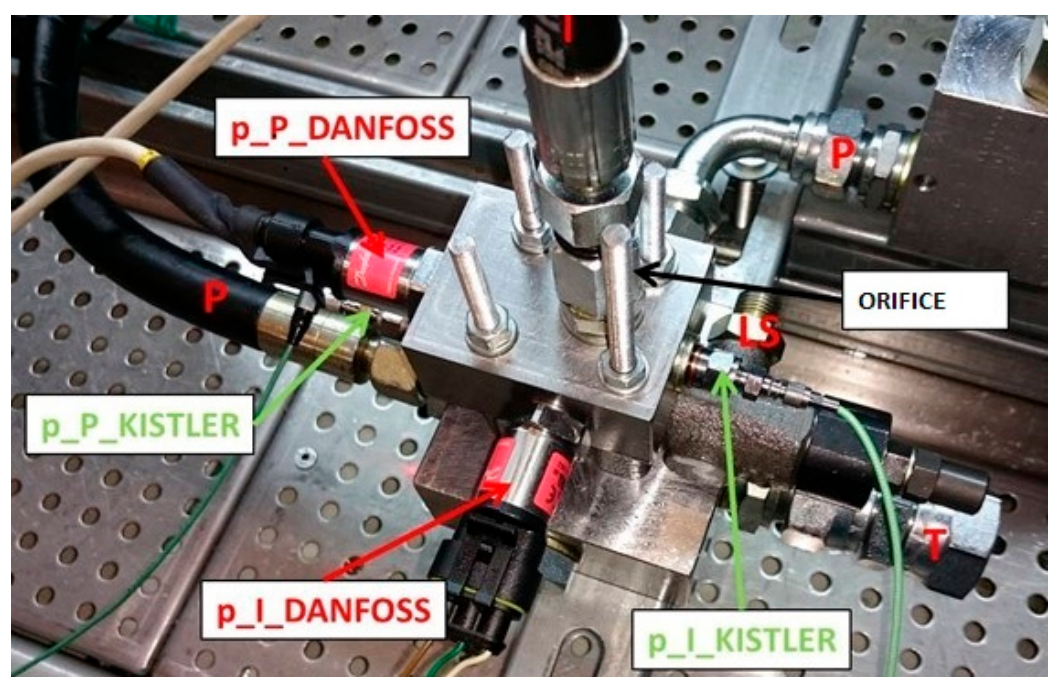

Figure 16. Component installed on the test bench with sensors.

In order to define the dynamic behavior of the component, the pressure oscillations at the inlet were assumed as "input data", while the pressure oscillations at the outlet were assumed as "output data". It is essential to acquire the pressure values at the inlet and outlet simultaneously; therefore, a double channel amplifier KISTLER ${ }^{\circledR} 5064$ was used together with the pressure transducers reported in Table 2; the sampling rate was set equal to $20 \mathrm{kHz}$.

Table 2. Main features of the installed sensors.

\begin{tabular}{ccc}
\hline Variable & Sensor & Main Features \\
\hline p_P, p_I & Kistler 6005 & $0-1000$ bar \\
p_P,p_I & Danfoss 1250 & $0-400$ bar $\pm 0.5 \% \mathrm{FS}$ \\
Amplifier & KISTLER $^{\circledR} 5064$ & Bandwidth $1 \mathrm{kHz}$ \\
\end{tabular}

During the tests, the pump speed was changed from $120 \mathrm{rpm}$ to $3000 \mathrm{rpm}$ in order to cover the frequency range from $20 \mathrm{~Hz}$ to $500 \mathrm{~Hz}$, being that the gear pump had 10 teeth. This range is suitable for the investigation, because the theoretical natural frequency of the 
component is about $300 \mathrm{~Hz}$. In Figure 17, the pressure oscillations measured at the inlet, P_P, and at the outlet, P_I, are reported with a pump speed of $600 \mathrm{rpm}$, which corresponds to the fundamental frequency of $100 \mathrm{~Hz}$; the average inlet pressure was set to $30 \mathrm{bar}$ and the calibrated orifice with a diameter equal to $1.2 \mathrm{~mm}$. The Fourier transform of both signals are reported in Figure 18, where the first harmonic at $100 \mathrm{~Hz}$ is clearly visible.

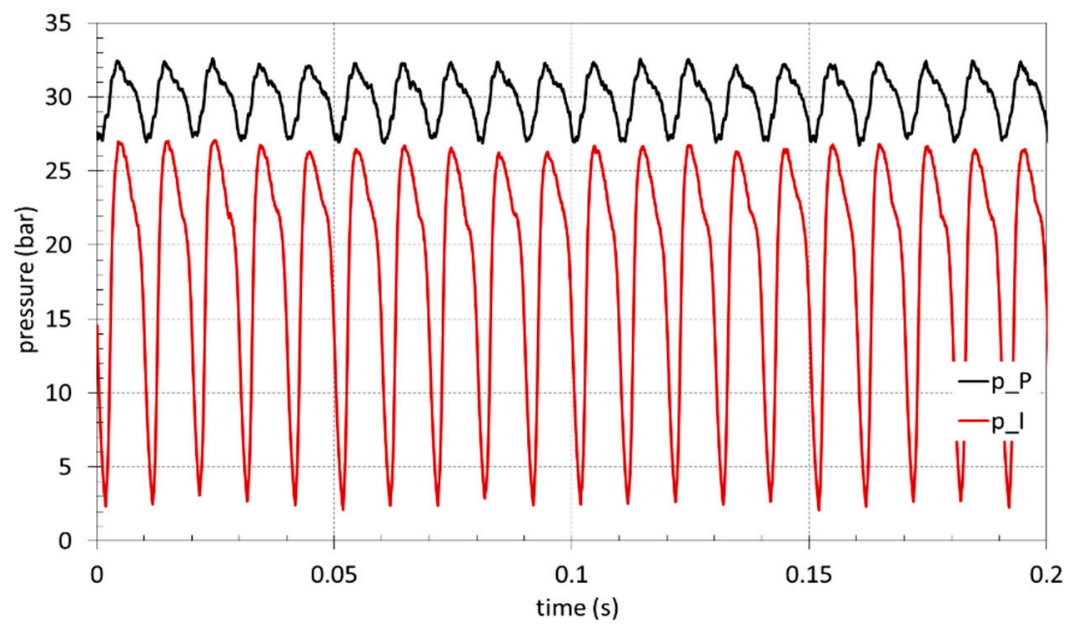

Figure 17. Experimental pressure measured at the inlet p_P and outlet p_I.

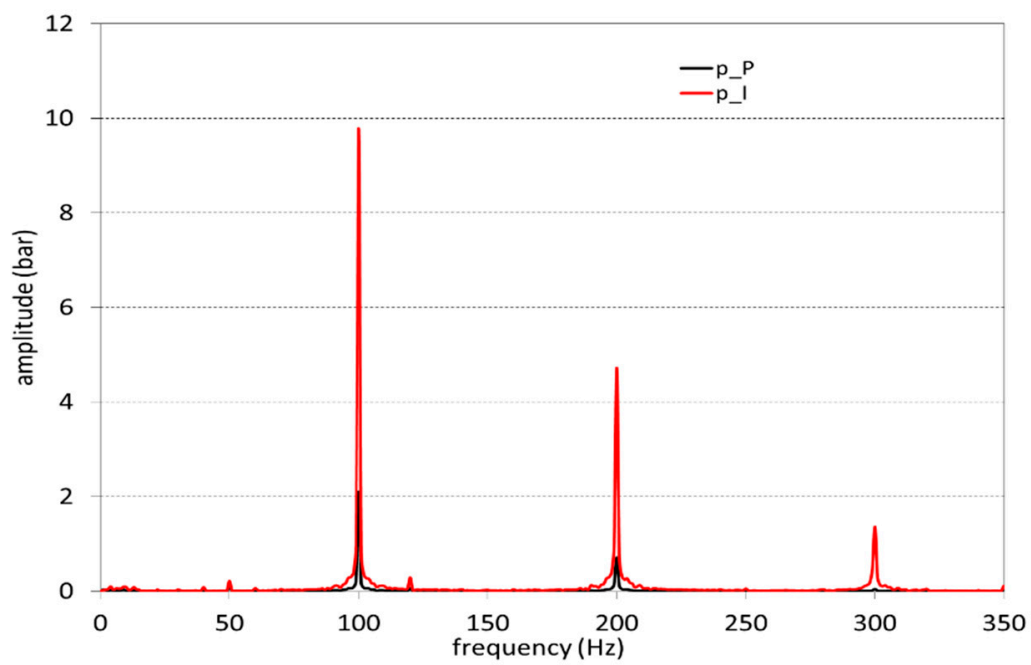

Figure 18. Fourier transform of the measured pressure p_P and p_I.

Starting from the amplitude of the first harmonic of both signals, the ratio between them was computed as a function of the frequency that was changed from $20 \mathrm{~Hz}$ to $500 \mathrm{~Hz}$ varying the pump speed:

$$
\mathrm{A}(\mathrm{f})=\frac{\left|\mathrm{A}_{p_{-} I}(\mathrm{f})\right|}{\left|\mathrm{A}_{p_{-} P}(\mathrm{f})\right|}
$$

In Figure 19 the Bode diagrams are reported with setting of the average inlet pressure at 30 and 50 bar and using an orifice with a diameter of 0.75 and $1.2 \mathrm{~mm}$. 


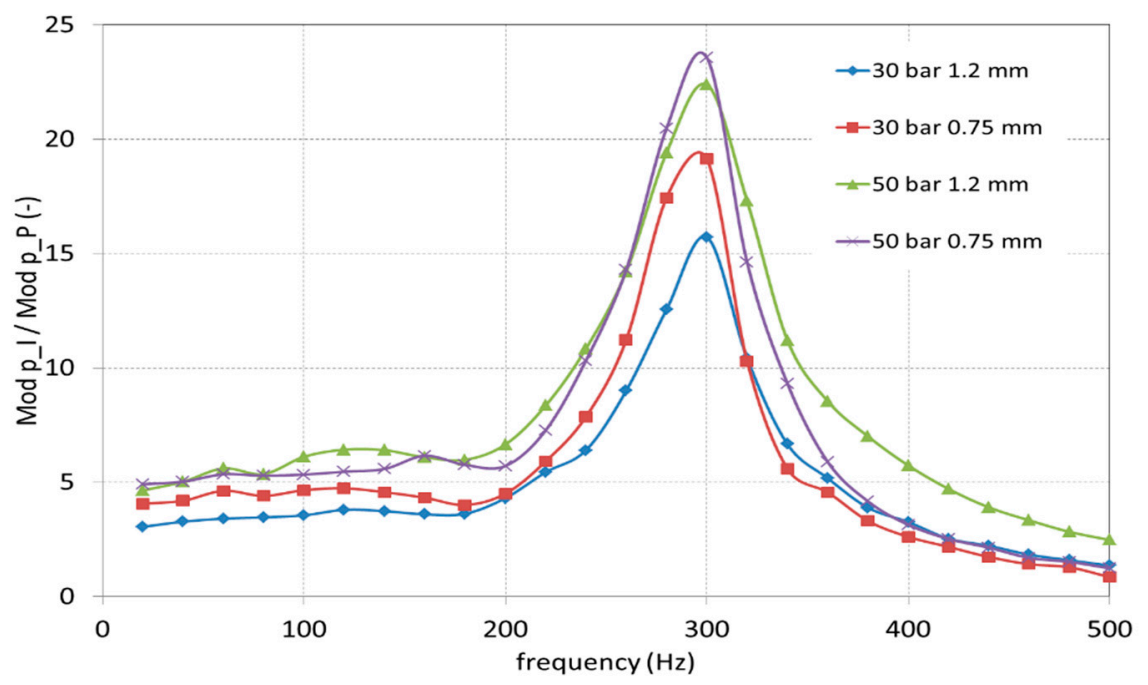

Figure 19. Experimental Bode diagram of the LS control.

All Bode plots showed an underdamped system behavior, and the resonance frequency was always around $300 \mathrm{~Hz}$ in all the conditions investigated. This is a significant result because the resonance frequency can be theoretically calculated with Equation (19):

$$
\omega_{\mathrm{n}}=\sqrt{\frac{\mathrm{k}_{\mathrm{tot}}}{\mathrm{m}_{\mathrm{tot}}}} \frac{1}{2 \pi}=294 \mathrm{~Hz}
$$

where $\mathrm{k}$ is the spring stiffness, and $\mathrm{m}$ is the total mass of the displaced components.

\section{Evaluation of the Friction Coefficient}

The target of this activity is to define the viscous friction coefficient. The mathematical model of the LS control was developed in the Amesim environment; the sketch is reported in Figure 20.

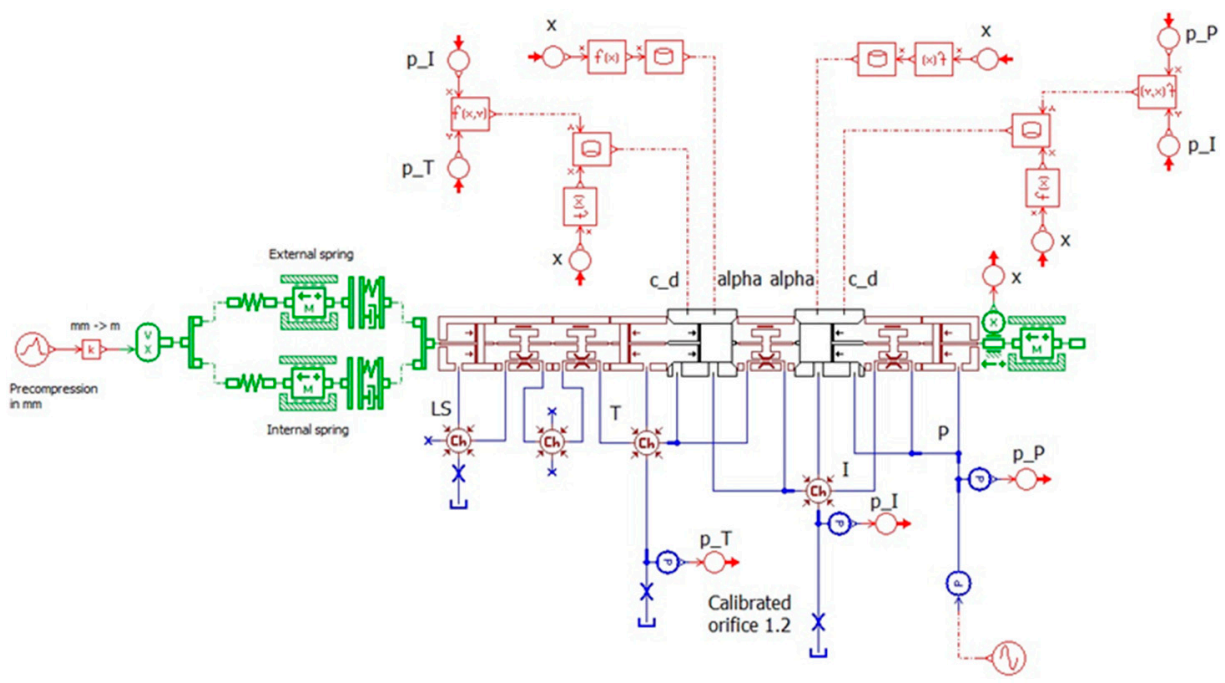

Figure 20. Simcenter Amesim sketch of the LS control.

The model calculates the instantaneous position and velocity of the spool using Newton's second law; the force acting on the spool are due to fluid pressure, spring force, hydrodynamic force, and viscous friction force. The friction force is represented by the term $c \cdot \dot{x}$ in Equation (4), where the coefficient $c$ needs to be evaluated. To define this coefficient, several simulations were carried out by setting the pressure ripple acquired during the 
tests as input for the model and changing the value of the viscous friction coefficient to obtain a satisfactory agreement with the experimental data. The results presented in Figures 21 and 22 show a satisfying agreement between numerical and experimental data. All these results were obtained by setting the viscous friction coefficient equal to $3.5 \mathrm{~N} /(\mathrm{m} / \mathrm{s})$. It must be considered that the ratio of the pressures was also affected by other parameters, such as the discharge coefficient of the flow area. However, the underdamped system behavior and the resonance frequency were correctly estimated.

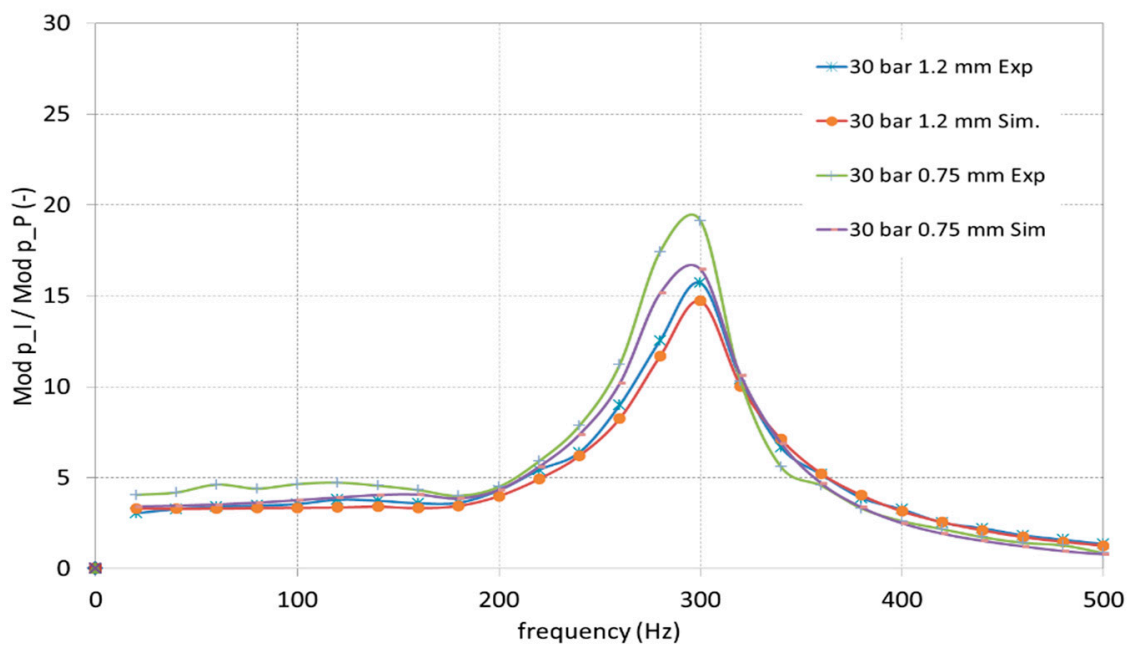

Figure 21. Comparison between experimental and simulated Bode diagrams-input pressure 30 bar.

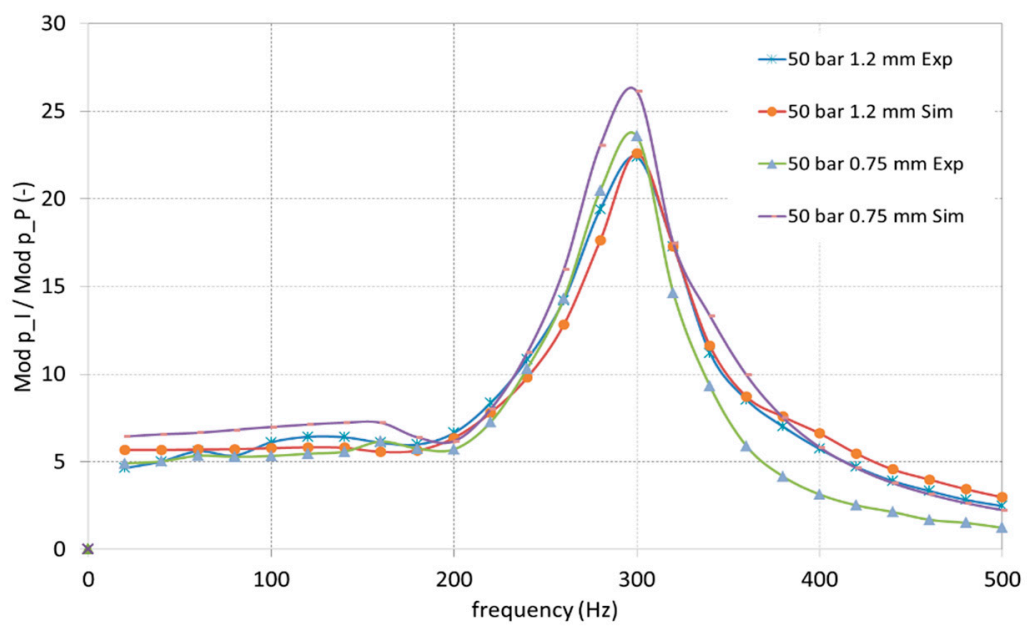

Figure 22. Comparison between experimental and simulated Bode diagrams—input pressure 50 bar.

\section{Discussion}

The methodologies presented are alternative ways for measuring the friction coefficient with respect to the installation of a displacement transducer that has the drawback of altering the displaced masses and friction losses. To analyze the effects of the presence of a linear variable displacement transducer (LVDT), further tests were carried out at the University of Parma. Figure 23 reports the LVDT mounted on the component. 


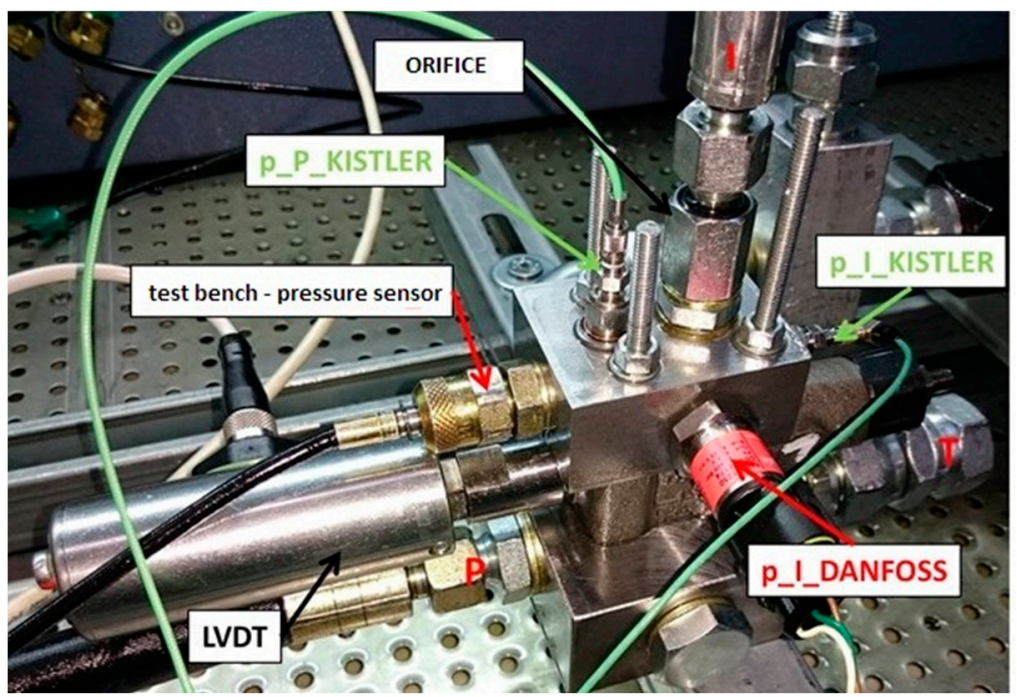

Figure 23. Component installed on the test bench with LVDT transducer (second method).

With this new configuration, the second method procedure was repeated, and the results obtained are reported in Figure 24.

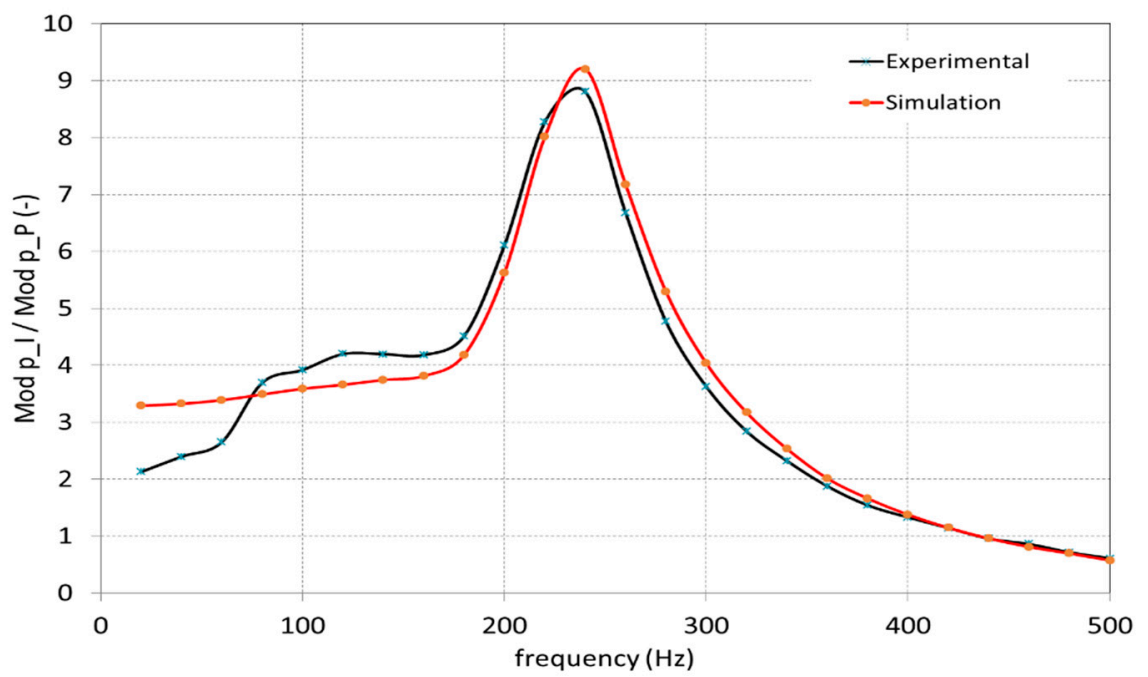

Figure 24. Comparison between experimental and simulated Bode diagrams (30 bar, $1.2 \mathrm{~mm}$ ); LVDT installed.

The resonance value was found at a lower value due to the increased mass of the displaced elements. With the theoretical formula a value of $237 \mathrm{~Hz}$ was found that, once again, is very similar to the resonance value shown in the diagrams. The mathematical model was able to reproduce the experimental outcomes by setting the friction coefficient equal to $7 \mathrm{~N} /(\mathrm{m} / \mathrm{s})$, which is a significantly higher value with respect to what was found without the LVDT connected to the LS control spool. These latter results point out how a traditional approach based on the measurement of the spool displacement with an LVDT leads to an incorrect value of the friction coefficient.

Both presented methods lead to the same value of the viscous friction coefficient $(3.5-4.0 \mathrm{~N} /(\mathrm{m} / \mathrm{s}))$; then it is possible to say that the methods validate one each other. The first method is based on a rigorous mathematical description of the phenomenon that correlates the fluid pressure along the pipe; this method required a servovalve and a simultaneous acquisition of the pressures. The second method is mainly based on the experimental evidence, starting from the obvious correlation between the pressure 
oscillations at the outlet and the spool oscillations forced by a known inlet pressure ripple; this method has shown experimental results that firstly have reproduced the resonance frequency, which is easily calculable, and secondarily the dynamic behavior has been simulated setting a viscous friction coefficient with results equal to the value found with the first method.

The first method has the advantage that all parameters of the excitation pressure (frequency, mean value, amplitude, and even waveform) can be selected independently, while one of the strengths of the second method is that it is easier to generate quite high frequencies by means of the gear pump. As far as the complexity of the circuit layout is concerned, the first method does not require a circuit connected to all valve ports, since only the connection of the pipe is needed, while the advantage of the second is that the circuit for the generation of the flow rate is simpler.

The friction coefficient can be calculated with equations available in the literature [18], equations that are often implemented in the main lumped parameter commercial simulation tools $[19,20]$. In [18] the coefficient is calculated assuming a laminar gap with constant height $h$ around the spool. Based on Newton's law, the shear stress $\tau$, defined as the ratio between the friction force $F_{f}$ and the contact surface $S$, is given by Equation (20):

$$
\tau=\frac{F_{f}}{S}=\mu \frac{v}{h}
$$

where $\mathrm{v}$ is the relative sliding velocity. Hence, the coefficient of proportionality between the force and the velocity is

$$
c=\mu \frac{S}{h}
$$

However, if Equation (21) is applied for this valve, a value of $\mathrm{c}$ around $1 \mathrm{~N} /(\mathrm{m} / \mathrm{s})$ is obtained. This value is much lower with respect to what found in this paper. A possible justification of this discrepancy can be the oversimplified hypothesis that considers the spool perfectly coaxial with respect to the housing. Since the clearance appears in the denominator, it is evident that any misalignment (eccentricity and tilt) can have a strong influence on the viscous friction coefficient. Hence, the value given by Equation (21) could represent a minimum value for the coefficient in ideal conditions.

Finally, the methodologies presented can be applied at different hydraulic components with similar coupling between sliding body and housing.

\section{Conclusions}

In this paper, two methodologies were presented to define the viscous friction coefficient in a hydraulic component where the sliding body has a very common shape like a spool. Both methods do not require the installation of a spool displacement transducer, but they are based on alternative experimental procedures. For both methods, the value of the viscous friction coefficient comes out from the application of the corresponding mathematical model, where the coefficient has been properly set in order to calibrate the models and to reproduce the experimental data. Since the experimental approaches presented in this paper are completely different between them, as well as the mathematical models adopted for reproducing the experimental outcomes, the value found for the coefficient can be considered reliable, and as a matter of fact, each method validates the other.

Author Contributions: Conceptualization, M.R. and P.C.; methodology, M.R., P.C. and A.L.; software, M.R. and P.C.; validation, M.R. and P.C.; writing—original draft preparation, M.R. and P.C.; writingreview and editing, M.R., P.C. and A.L. All authors have read and agreed to the published version of the manuscript.

Funding: This research received no external funding.

Data Availability Statement: The data presented in this study are available on request from the corresponding author. The data are not publicly available due to privacy reasons. 
Conflicts of Interest: The authors declare no conflict of interest.

\section{References}

1. Fresia, P.; Rundo, M. Lumped parameter model and experimental tests on a pressure limiter for variable displacement pumps. E3S Web Conf. 2020, 197. [CrossRef]

2. Ionescu, F. Some aspects concerning nonlinear mathematical modeling and behaviour of hydraulic elements and systems. Nonlinear Anal. Theory Methods Appl. 1997, 30, 1447-1460. [CrossRef]

3. Yanada, H.; Sekikawa, Y. Modeling of dynamic behaviors of friction. Mechatronics 2008, 18, 330-339. [CrossRef]

4. Feng, H.; Qiao, W.; Yin, C.; Yu, H.; Cao, D. Identification and compensation of non-linear friction for a electro-hydraulic system. Mech. Mach. Theory 2019, 141, 1-13. [CrossRef]

5. Dell'Amico, A.; Krus, P. Modelling and experimental validation of a nonlinear proportional solenoid pressure control valve. Int. J. Fluid Power 2016, 17, 90-101. [CrossRef]

6. Natali, E.; Zardin, B.; Cillo, G.; Borghi, M. Modelling of hydraulic locking balancing circumferential grooves for servo-cylinders' piston. In Proceedings of the BATH/ASME Symposium on Fluid Power and Motion Control, Bath, UK, 9-11 September 2020. [CrossRef]

7. Zeiger, G.; Akers, A. Dynamic analysis of an axial piston pump swashplate control. Proc. Inst. Mech. Eng. 1986, 200, 49-58. [CrossRef]

8. Mandal, N.P.; Saha, R.; Mookherjee, S.; Sanyal, D. Pressure compensator design for a swash plate axial piston pump. J. Dyn. Syst. Meas. Control 2014, 136, 021001. [CrossRef]

9. Manring, N.D.; Mehta, V.S. Physical limitations for the bandwidth frequency of a pressure controlled axial-piston pump. J. Dyn. Syst. Meas. Control 2011, 133, 061005. [CrossRef]

10. Casoli, P.; Anthony, A.; Rigosi, M. Modeling of an Excavator System-Semi Empirical Hydraulic Pump Model. SAE Int. J. Commer. Veh. 2011, 4, 242-255. [CrossRef]

11. Casoli, P.; Anthony, A.; Ricco, L. Modeling simulation and experimental verification of an excavator hydraulic system-Load sensing flow sharing valve model. SAE Tech. Paper 2012. [CrossRef]

12. Casoli, P.; Pompini, N.; Riccò, L. Simulation of an excavator hydraulic system using nonlinear mathematical models. Stroj. Vestn J. Mech. Eng. 2015, 61, 583-593. [CrossRef]

13. Bedotti, A.; Campanini, F.; Pastori, M.; Riccò, L.; Casoli, P. Energy saving solutions for a hydraulic excavator. Energy Procedia 2017, 126, 1099-1106. [CrossRef]

14. Casoli, P.; Riccò, L.; Campanini, F.; Lettini, A.; Dolcin, C. Mathematical model of a hydraulic excavator for fuel consumption predictions. In Proceedings of the ASME/BATH 2015 Symposium on Fluid Power and Motion Control, FPMC 2015, Chicago, IL, USA, 12-14 October 2015. [CrossRef]

15. Padovani, D.; Rundo, M.; Altare, G. The working hydraulics of valve-controlled mobile machines: Classification and review. J. Dyn. Syst. Meas. Control 2020, 142. [CrossRef]

16. Rundo, M. On the dynamics of pressure relief valves with external pilot for ICE lubrication. In Proceedings of the ASME International Mechanical Engineering Congress and Exposition, Montreal, QC, Canada, 14-20 November 2014. [CrossRef]

17. Corvaglia, A.; Ferrari, A.; Rundo, M.; Vento, O. Three-dimensional model of an external gear pump with an experimental evaluation of the flow ripple. Proc. Inst. Mech. Eng. Part C J. Mech. Eng. Sci. 2021, 235, 1097-1105. [CrossRef]

18. Blackburn, J.F.; Reethof, G.; Shearer, J.L. Fluid Power Control; The M.I.T. Press: Cambridge, MA, USA, 1960.

19. Siemens Digital Industry Software. Simcenter Amesim 2019.2 User Manual; Siemens Digital Industry Software: Plato, TX, USA, 2019.

20. Gamma Technologies. GT-Suite 2017 User Manual; Gamma Technologies: Westmont, IL, USA, 2017. 